\title{
Stokes Drift in Topographic Waves over an Enclosed Basin Shelf
}

\author{
PEYGHAM GHAFFARI \\ Department of Arctic R\&D, Akvaplan-Niva, Oslo, Norway \\ JAN ERIK H. WEBER \\ Department of Geosciences, University of Oslo, Oslo, Norway \\ Ole Anders NøST AND Magnus Drivdal \\ Department of Arctic R\&D, Akvaplan-Niva, Trondheim, Norway
}

(Manuscript received 21 May 2019, in final form 14 February 2020)

\begin{abstract}
The effect of the continental shelf wave on the flow field over the southern shelf of the Caspian Sea (CS) as the largest enclosed basin of the world, is investigated. Considerable currents with subinertial time scales are observed over the continental shelf in the southern CS. For variations in the surface layer with typical periods of 1 day, local episodic wind events appear to be the driving force. For longer time scales, it is suggested that the observed currents are due to passing continental shelf waves. Measurements over the continental shelf and shelf slope, showing periods of 2-6 days, indicate the presence of such waves. Combined with theory and numerical modeling, the amplitude of the continental shelf wave modes at the coast is assessed from current meter observations. It is demonstrated that the mean drift velocity (the Stokes drift) for long continental shelf waves is determined entirely by the shelf geometry. For the actual shelf mode, it is shown that the associated Stokes drift constitute a nonnegligible mean current along the shelf. This current should be taken into account when assessing the transport of biological material and neutral tracers along the southern coast of the CS.
\end{abstract}

\section{Introduction}

Flow-field observations in diverse enclosed water bodies indicate the existence of oscillations with a period of a few days (Mysak 1984). Measurements from stations on the southern continental shelf of the Caspian Sea (CS) with negligible tidal motion, demonstrate the importance of the sea breeze as periodic surface forcing on diurnal scales (see, e.g., Ghaffari and Chegini 2010; Ghaffari et al. 2010). However, in Ghaffari and Chegini (2010) ADCP measurements from a station in the shallow part of the southeastern CS are presented, showing sporadic strong currents with a frequency scale of $1 \mathrm{cpd}$ (cpd is cycles per day), as well as events of strong currents with a frequency range of several days $(\sim 0.17 \mathrm{cpd})$. We here present current measurements from the southern part of the Caspian shelf. In particular we focus on motion over

Corresponding author: Peygham Ghaffari, peygham.ghaffari@ akvaplan.niva.no the shelf slope with periods of several days. We argue that this signifies the presence of a continental shelf wave (hereafter referred to as CSW). Evidence for the existence of CSW in the ocean has been found through analysis of current meter and sea level records (see, e.g., Cutchin and Smith 1973). In the northern and middle part of the CS, such waves with similar periods have been recorded previously (Bondarenko 2001). They can be generated by strong winds (e.g., Gill and Schuman 1974) anywhere on the western part of the CS where the bottom topography is favorable. Since CSWs are trapped over the slope, and propagate with shallow water to the right in the Northern Hemisphere (Longuet-Higgins 1965), they reach the southern shelf, eventually modified by local winds and changing bottom topography.

Basically, CSWs owe their existence to the conservation of potential vorticity in an inviscid rotating ocean. On an $f$ plane, the displacement of vertical water columns across bottom contours creates alternating positive and negative relative vorticity. The waves created 
by this alternating vorticity have a phase that propagates with shallow water to the right in the Northern Hemisphere. Since the shelf regions are important spawning areas for fish as well as sites for offshore oil exploration, and (more recently) fish and wind farms, the currents induced by CSWs have been studied extensively (Röhrs et al. 2014). Thorough information on CSWs topic can be obtained from excellent textbooks (LeBlond and Mysak 1978; Gill 1982). A more recent review is given by Brink (1991).

It is well known that periodic wave motion in fluids may induce a net transport of particles (e.g., Stokes 1847). In addition, if the wave momentum attenuates due to friction in the fluid, mean momentum is transferred from the wave motion to mean Eulerian currents (Longuet-Higgins 1953). While the latter current depends crucially on how the effect of friction is modeled, the Stokes drift velocity is virtually independent of friction and can be obtained from the inviscid equations. Traditionally the Stokes drift is studied in relation to surface gravity waves (see, e.g., Phillips 1977). For gravity waves that are trapped by bottom topography, we refer to the paper by Kenyon (1969) on Stokes drift in edge waves. Drivdal et al. (2016) derived the dispersion relation for CSWs for the idealized southwest Norwegian shelf. The nonlinear mean drift induced by barotropic CSWs is studied theoretically by Weber and Drivdal (2012). The Stokes drift is also part of the more comprehensive solution for the drift current in edge waves by Weber and Ghaffari (2009) and Ghaffari and Weber (2014).

In this paper, we will focus on the evidence of CSWs in the CS. Additionally, the wave amplitudes will be estimated from flow field observations. Hence, we can calculate the nonlinear Stokes drift velocity for the wave modes in question. Our results provide new information concerning the net transport along the southern CS shelf.

The rest of this paper is organized as follows: in section 2, we present the study area and revisit some flow field observation over the shelf slope of this region. Section 3 represents the mathematical formulation, where we study the properties of linear CSWs related to the specific geometry of the CS shelf. In section 4, we discuss indications of CSW in relation to observations and mathematical formulation. Section 5 is devoted to the numerical experiments using realistic and idealized impulsive atmospheric forcing. In section 6, we derive the Stokes drift velocity for the lowest shelf modes. Finally, a brief discussion and concluding remarks are provided in section 7 .

\section{Study area and observation}

The study area is located on the southern part of the CS shelf; see Fig. 1. This region is subject to strong

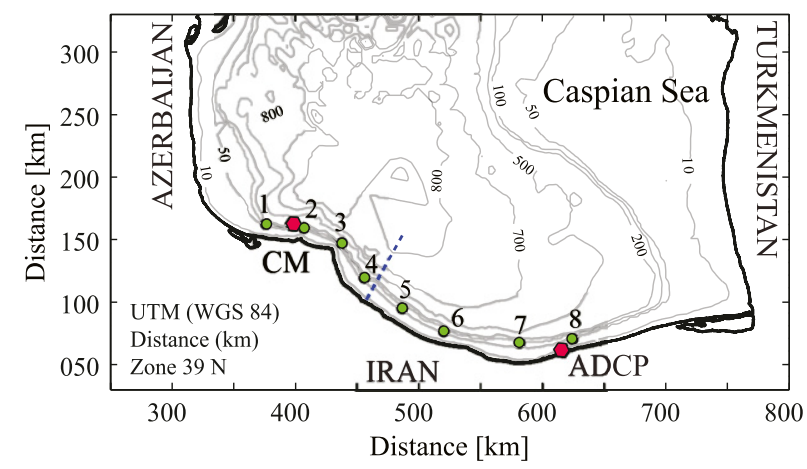

FIG. 1. Study area: red circles are shelf-current recording locations in the eastern and western parts in the southern basin of the CS. Green points indicate locations where time series of the velocity field are taken (counting from west to east).

alongshore currents (see, e.g., Ghaffari and Chegini 2010; Zaker et al. 2011). Since the theory of shelf waves predicts prominent associated horizontal current fluctuations, and modest sea level fluctuations (Cutchin and Smith 1973), we mainly focus on the current measurements in this study. To more closely examine the existence and behavior of CSW over the southern shelf of the CS, we use bottom-mounted ADCP measurements from the eastern continental margin (Fig. 2) and current meter records (Fig. 5) from the western shelf slope (see Ghaffari and Chegini 2010; Ghaffari et al. 2013). Wind parameters were also recorded in the vicinity of the observation position. All datasets for wind and currents were decomposed in along- and cross-shore directions.

The ADCP observations are obtained at a station $4 \mathrm{~km}$ off the coast, where the depth is $14 \mathrm{~m}$. Spectral analyses of the middepth current and wind time series for both along- and cross-shore components (Fig. 2) reveal prevalence of the low-frequency signals, with dominant peaks at synoptic time scale on the order of several days ( $\sim 2-6$ days). The along- and cross-shore current components show roughly a similar amount of energy at frequencies higher than $0.08 \mathrm{cph}$, while the semidiurnal and diurnal frequencies are shown mainly on the cross-shore spectrum. Wavelet analysis of wind stress and current at middepth time series are used to localize the time variation of the low-frequency signals. Both along- and cross-shore components of wind show at least two distinct episodes with local energy maximums at low frequencies ( $\sim 2-6$ days) on 10-17 August and 6-16 September. The current wavelet spectrums show few periods when the diurnal variation is significant. However, the most prevailing band of significant variability occurs in periods longer than diurnal scale. Both along- and cross-shore wavelet spectrums reveal a broader and less distinct local energy maximum at low frequencies ( $\sim 2-6$ days). The scale-averaged variance 

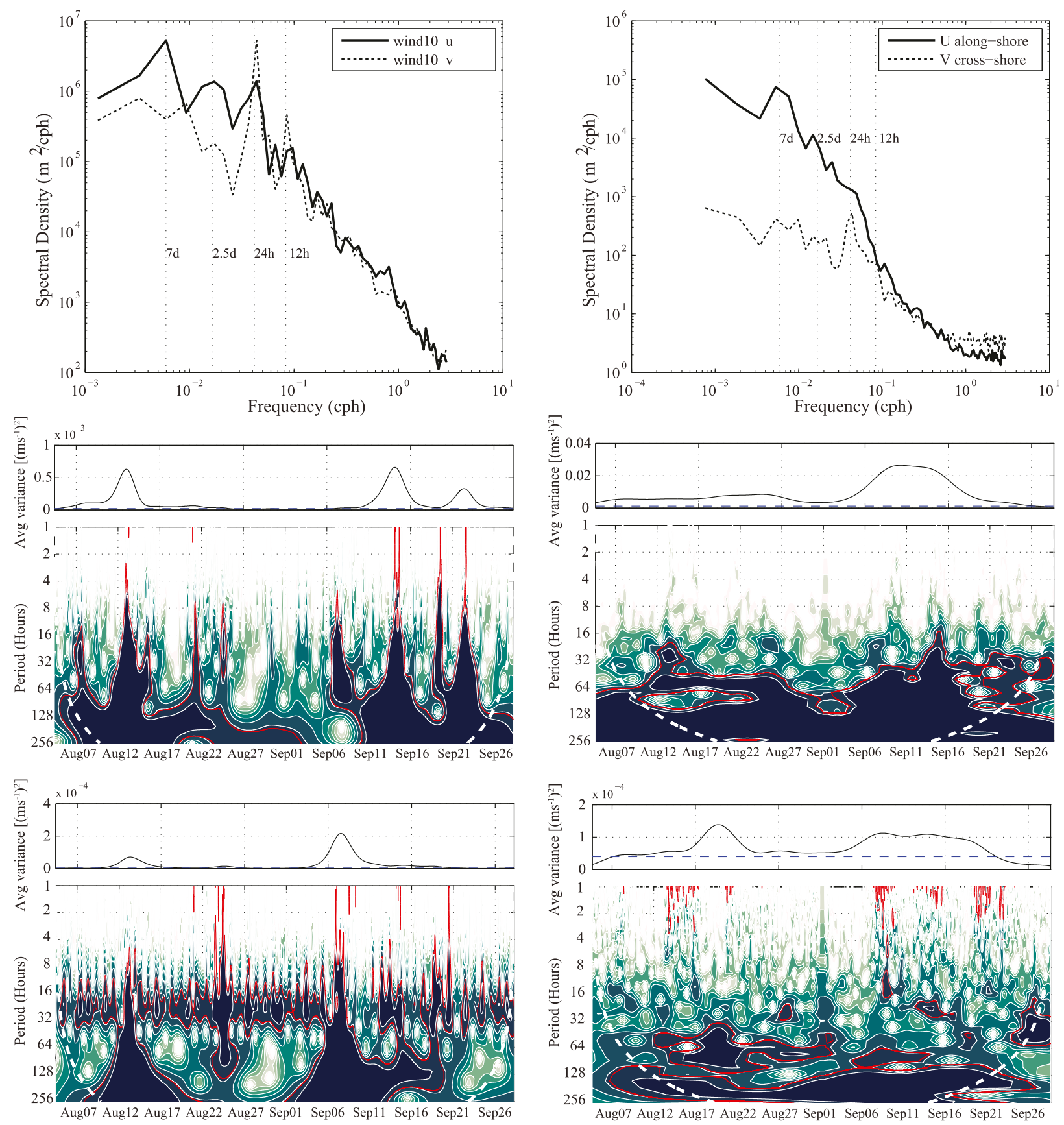

FIG. 2. Measurements from the southeastern Caspian Sea (Ghaffari and Chegini 2010). (left) Wind ( $U_{10}$ and $\left.V_{10}\right)$ and (right) current at the middepth. (top) Spectral analysis of alongshore (solid line) and cross-shore (dashed line) components of wind speed and current. (middle) Wavelet analysis of the alongshore component of wind stress and middepth current. (bottom) Wavelet analysis of the cross-shore component of wind stress and middepth current. The $95 \%$ confidence level for wavelet transform is indicated with red contours. For each wavelet panel, a scale-averaged variance over the 2.5 -day band is paired, where a $95 \%$ significance level for averaged variance is indicated with a blue dashed line.

(averaged between 2.5 and 6 days) shows that the flow field variability at this frequency band is almost present during more than $90 \%$ of the ADCP listening period. Rotary power spectra of hourly filtered current and wind data (Fig. 9 in Ghaffari and Chegini 2010) reveals that in diurnal and semidiurnal bands, currents are manifested in positive sense which implies an anticlockwise rotation forced by the local wind (sea breeze). Lower-frequency 

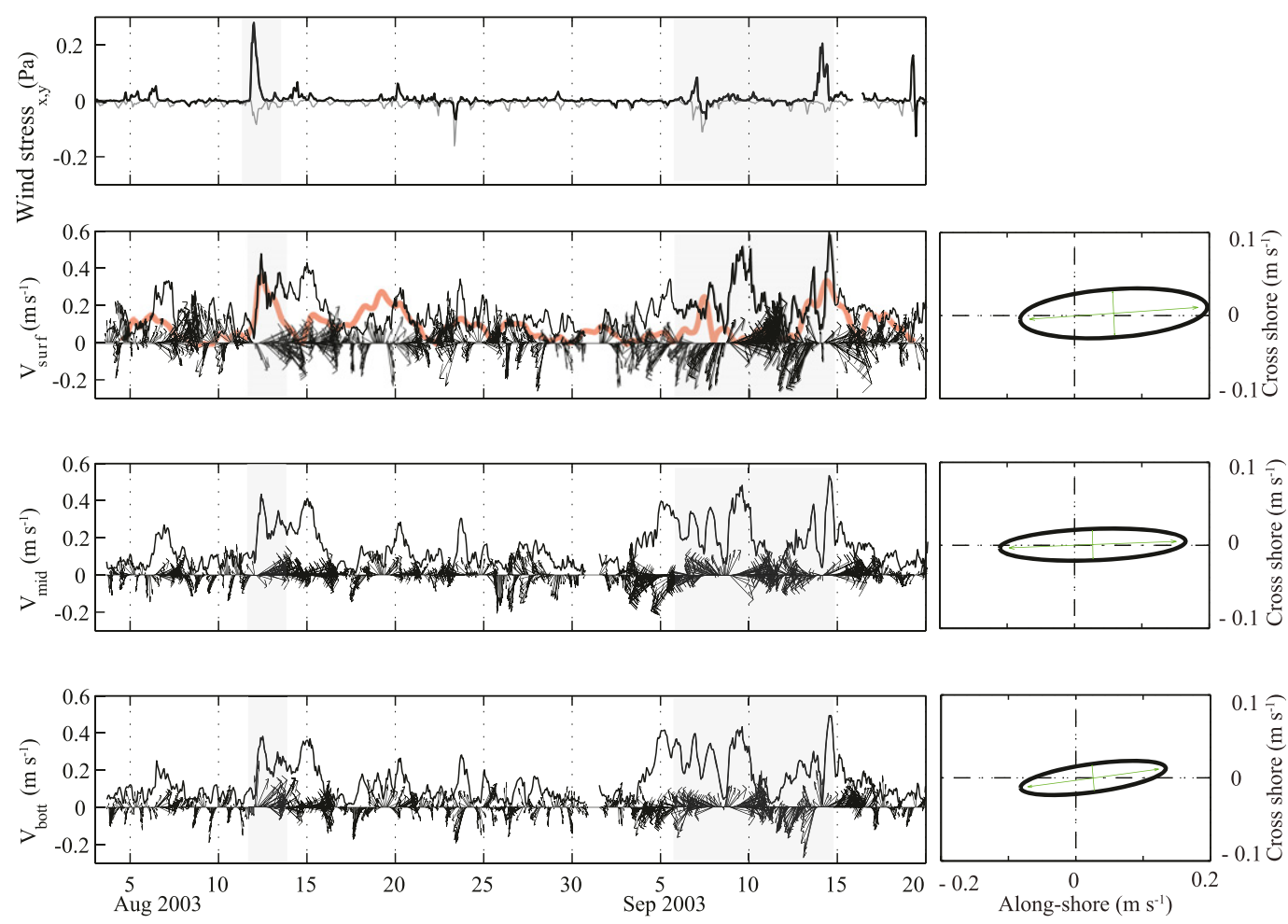

FIG. 3. Measurements from the southeastern Caspian Sea (Ghaffari and Chegini 2010). (first row) Alongshore wind stress $\tau_{1}$ and cross-shore wind stress $\tau_{2}$, (second row) current velocity at surface, (third row) current velocity at mid depth, and (fourth row) current velocity at the bottom. The solid gray line in the current plots represents magnitude. The red curve represents current velocity based on 2D numerical model.

signals ( $\sim 6$ days) also indicate a weakly rotational motion. A more in-depth analysis of this dataset can be found in Ghaffari and Chegini (2010). Wind stress time series and velocity vector plot for the ADCP observations at surface, middepth, and bottom are presented in Fig. 3, respectively. The figure implies that the main energy of the flow field is located in the barotropic mode. Variance ellipses for the daily averaged currents for three depths are given in the right panels. These have high eccentricities and the principal axes of the variability are closely aligned. The alignment and magnitude of the ellipses suggests the currents are fairly barotropic. To quantify this, we calculated the barotropic fraction of energy:

$$
R=\frac{H\langle\bar{u}\rangle}{\left[H\left\langle\bar{u}^{2}\right\rangle+\left\langle\sum_{n=1}^{N}\left(u^{\prime}\right)^{2} d z\right\rangle\right]},
$$

where $N$ is the total number of the depth layers, $\bar{u}$ and $u^{\prime}$ are depth-averaged and depth-varying velocities, respectively. The angle brackets in (1) are time averages and $H$ is the depth at the bottom-mounted ADCP location. The depth-averaged velocity accounts for $95.5 \%$ of the total variance in the flow field. Observations show that the currents basically are barotropic with the mean amplitude is $\sim 0.2 \mathrm{~m} \mathrm{~s}^{-1}$ and periodic motion with periods from about 2 to 6 days is distinct. This fits well with earlier observations, for example, Bondarenko (2001), who reports currents with a similar order of amplitudes and periods in the northern and middle parts of the CS. Here, in particular, we are interested in the uppermost ADCP measurements ( $1 \mathrm{~m}$ below the surface), which will be considered as surface measurement hereafter. We consider two specific time intervals in 2003 for further analysis: 13-14 August and 8-14 September. The first interval is characterized by a strong alongshore sporadic wind stress followed by large alongshore velocities. In the second interval, the wind stress is moderate, while we have strong currents with a period of nearly 6 days. In this region, the wind speed fluctuates slightly and wind directions are almost fixed in the crossshore direction (the sea breeze direction). Forcing from the wind occurs on time scale from 1 day (the diurnal sea breeze and sporadic storm events) to periods up to 6 days (synoptic weather systems). This feature is quite different from that of the shelf current which magnitude strongly fluctuates, and which direction changes almost 


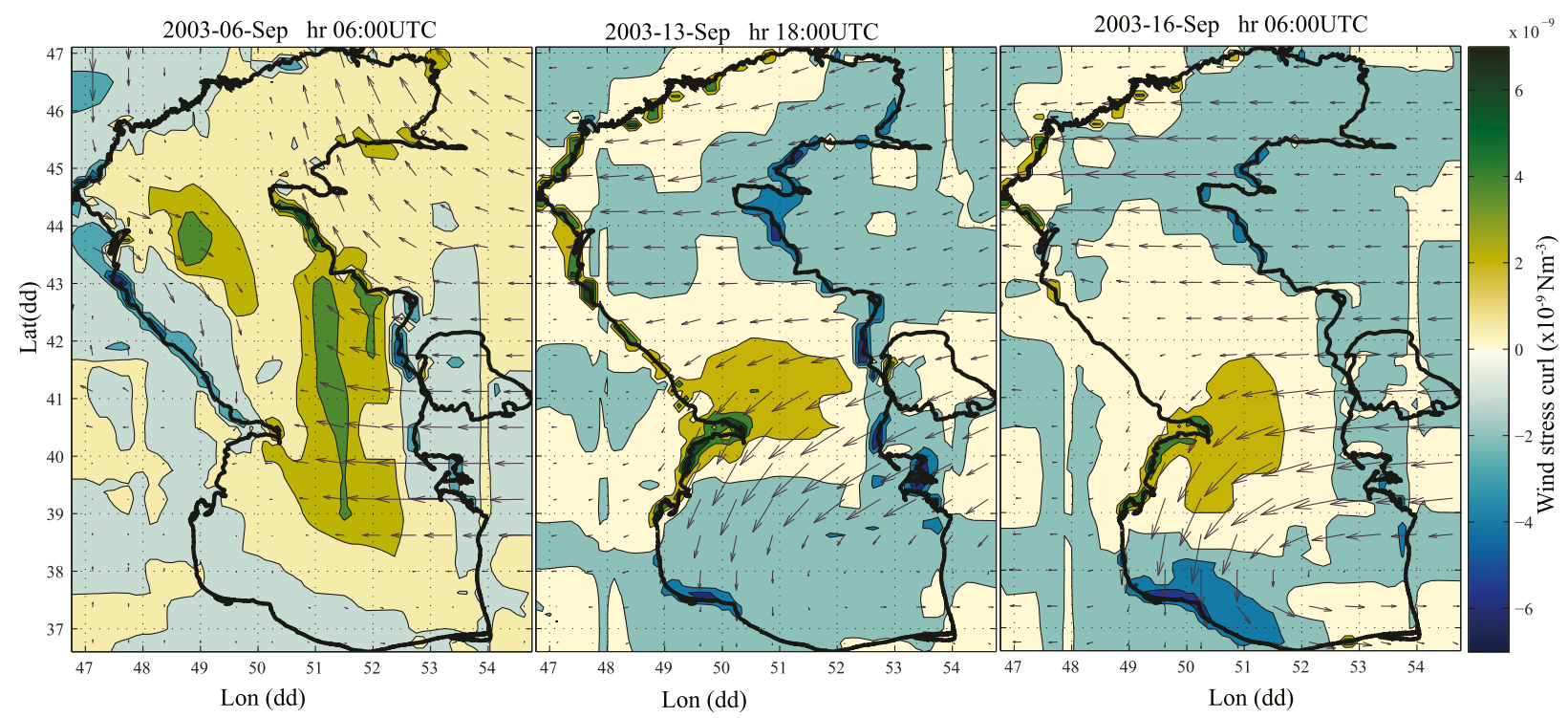

FIG. 4. Curl of wind stress mapped over the CS using the ERA5 reanalysis field representing those events that were individuated in Fig. 3.

$180^{\circ}$ in the alongshore direction rather frequently. This is evident from the measurements presented by Ghaffari and Chegini (2010); see Fig. 3. Wind stress curl maps over the entire CS for the second interval is shown in Fig. 4. The wind stress maps demonstrate strong wind over the central part which pushes toward the western coast of the CS. The periodic subinertial currents on the shelf in the second interval are probably not induced by the local winds, which are weak. It is clearly noticeable that due to the collision of northeast and southwest wind fronts strong wind events historically occur at the west coast of the CS (Bohluly et al. 2018). It is therefore natural to consider this region as the generation area for CSWs. Observations over the southwestern shelf slope of the CS (230-m isobaths, CM location Fig. 1) show an equivalent barotropic structure and quasi-periodic nature of the flow field in weak wind condition. Here, the depth-averaged velocity is accounts for $82 \%$ of the total variance in the mooring. This is consistent with previous results which suggested the flow field in the eastern part of the southern basin is nearly barotropic. This mooring has current meters at $3.5,65$, and $112 \mathrm{~m}$. Thus, the upper two are in the seasonal thermocline (which spans the upper $\sim 30 \mathrm{~m}$ in summer) and the surface Ekman layer. We focus on the deeper current records. In particular, we are interested in the data from the current meter at $112-\mathrm{m}$ depth. The local depth here is $230 \mathrm{~m}$, so this current meter should be located well below the surface Ekman layer and well above the frictional bottom layer. The squared coherences between the three time series are $0.6-0.8$ at periods longer than 3 days. So the low-frequency fluctuations have a reasonably large vertical coherence. As this mooring yields the best information about the flow in the basin interior, we use its currents for the subsequent analysis (for more details, see Ghaffari et al. 2013). Spectral density and wavelet analysis of the along- and cross-shore components of the velocity field (Fig. 5) also reveal that the most prevailing flow field variability (which is present $\sim 80 \%$ of the recording period) is located on the low-frequency band ( $\sim 2.5-6$ days). In Fig. 6 we present data for January 2005. To suppress all signals higher than $0.5 \mathrm{cpd}$, we applied a bandpass filter $(0.17-$ $0.5 \mathrm{cpd}$ ) to the along- and cross-shore current components. The wave-like behavior of the flow field is evident within the filtered frequency band. Our particular interest here is the quasi-periodic behavior of the cross-shore velocity component. Since this occurs over the steep part of the shelf, it indicates that water columns are moving back and forth across the isobaths, which is a necessary condition for maintaining CSWs.

Observations from both western and eastern sides of the southern Caspian shelf indicate the prevalence of the subdiurnal oscillation of flow field. The relatively weak relationship between the low-frequency alongshore currents and wind stress indicates that these currents were not mainly driven by local winds, and other forcing mechanisms should be brought into consideration. Considering the characteristics of the observed alongshore currents: peaks of energy at 2-6-day periods, uniformity across the depth, and weak correlation with the local wind stress suggest that CSWs are the most 

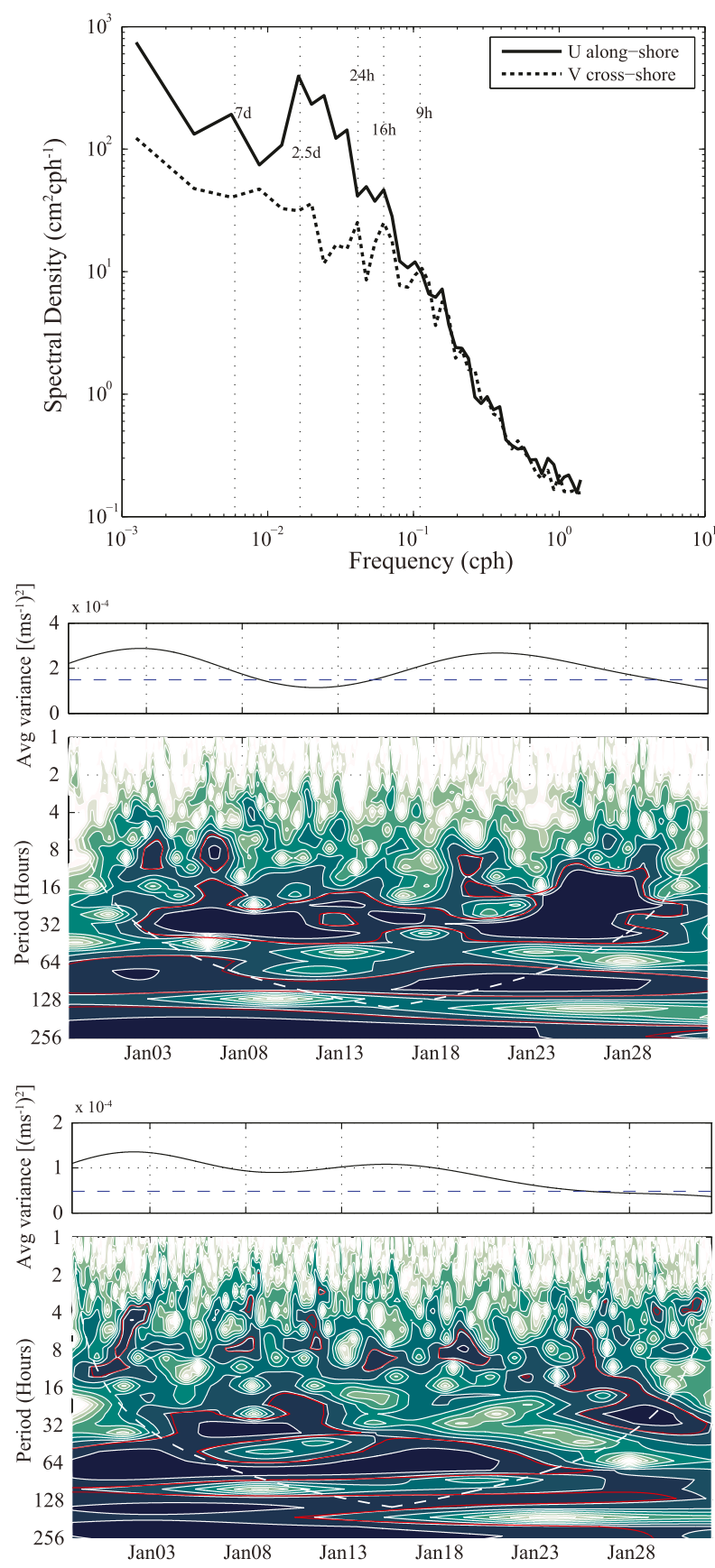

FIG. 5. Measurements from southwestern part of the Caspian shelf at 112-m depth. (top) Spectral analysis of alongshore (solid line) and cross-shore (dashed line) components of current. (middle) Wavelet analysis of the alongshore component of current at 112-m depth. (bottom) Wavelet analysis of the cross-shore component of current. The $95 \%$ confidence level for wavelet transform are indicated with red contours. For each wavelet panel, a scaleaveraged variance over the 2.5-day band is paired, where a $95 \%$ significance level for averaged variance is indicated with a blue dashed line.

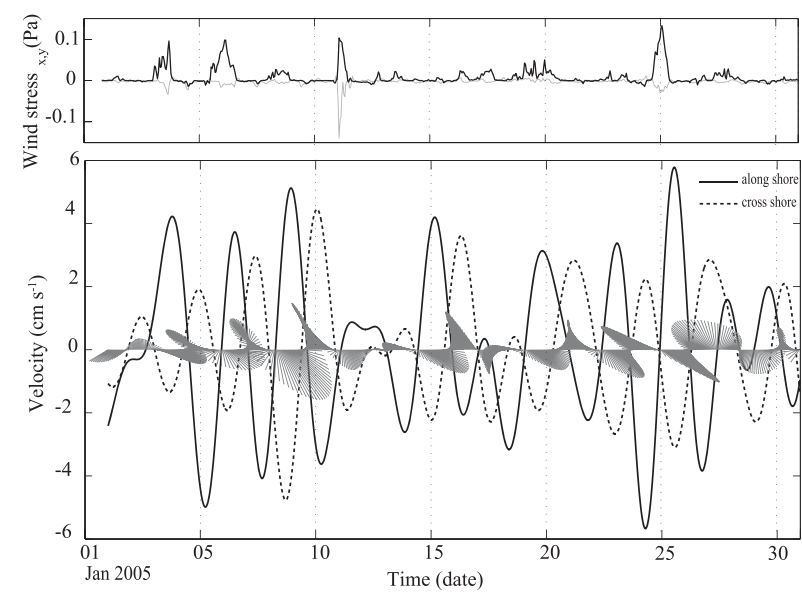

FIG. 6. Measurements at $112-\mathrm{m}$ depth and wind at $10 \mathrm{~m}$ in January 2005. (top) Along- and cross-shore wind stresses time series. (bottom) Bandpassed (0.17-0.5 cpd) current component at 112-m depth for the southwestern part of the CS.

likely candidate for producing such low-frequency currents over the southern shelf of the CS. The idea of CSWs in the CS is not new. Bondarenko (2001) attributes similar low-frequency currents in the central part of the CS to the presence of such waves. In the next section we analyze the dynamics of CSWs for an idealized shelf in the southern CS; see e.g., Fig. 7.

Under actual conditions in the surface sea layer, wind induced currents play a rather significant role. Our data show in the synoptic range of the current variability oscillations with periods from $2-3$ days to $1-3$ weeks prevail in the CS, that are reported previously by Baidin and Kosarev (1986). Based on Brink (1991), these oscillations are related to the synoptic variability of the direct wind impact and to coastal trapped waves, which are supported by present study as well.

\section{Mathematical formulation}

In our theoretical study, we place the $x$ axis along the coast and direct the $y$ axis toward the sea. The $z$ axis is vertically upward. The velocity components in the various directions are $(u, v, w)$, while the free surface is given by $z=\eta$. Buchwald and Adams (1968) considered freely propagating CSWs over two type of the shelves, that is, exponential shelf models with and without a flat continental shelf extension. Here, we consider a typical shelf in the southern CS, where the continental shelf is quite narrow. Hence, the southern Caspian shelf is well represented by the later model of Buchwald and Adams (1968), that is, $z=-H(y)$, where

$$
H=H_{0} \exp (2 b y), \quad 0 \leq y \leq B,
$$




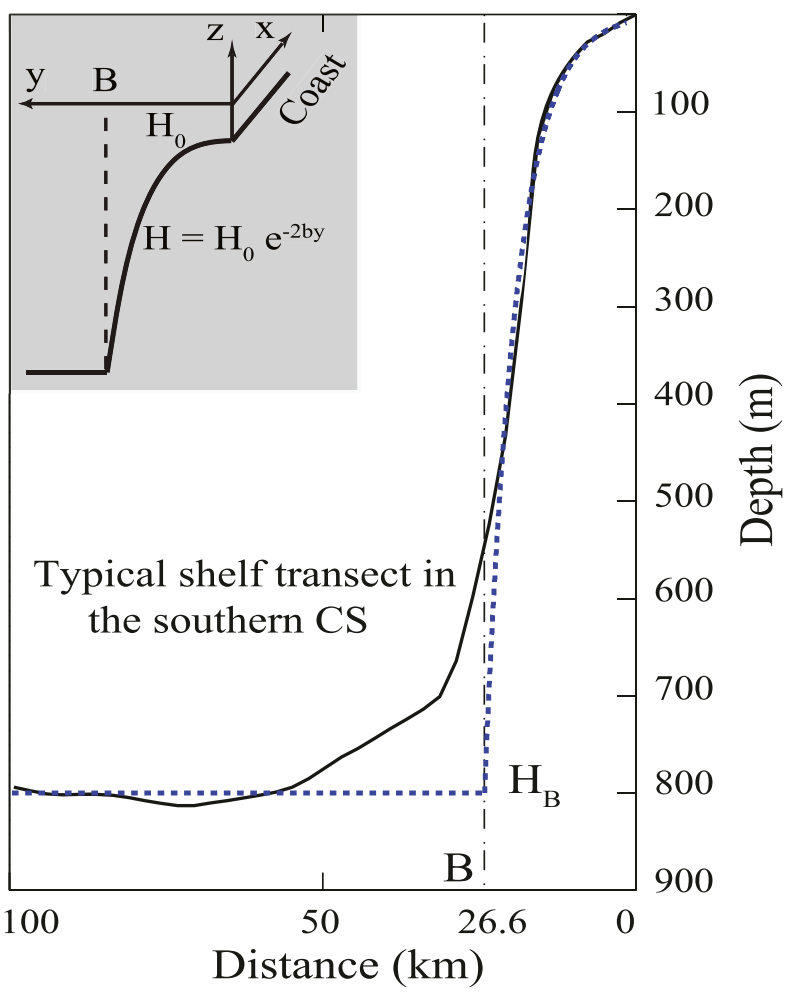

FIG. 7. Vertical shelf profile in the southwestern CS. The blue broken curve is the idealized exponential shelf profile (2). The inset at the top left shows an idealized shelf model sketch and coordinate system.

$$
H=H_{\max }, \quad y>B .
$$

Here $b$ is a positive constant describing the steepness of the shelf slope. Furthermore, the shelf width $B$ becomes $B=\ln \left(H_{\max } / H_{0}\right) / 2 b$. A sketch of the geometry and coordinate system is displayed in Fig. 1. For a more general configuration that allows an arbitrary flat shelf extension, we refer to the paper by Drivdal et al. (2016). For the study area in the southern part of the Caspian shelf, indicated in Fig. 7, we have approximately that $H_{0}=7.8 \mathrm{~m}, B=26.6 \times 10^{3} \mathrm{~m}$, and $b=$ $1.37 \times 10^{-4} \mathrm{~m}^{-1}$. We note from Fig. 7 that the idealized profile (2) fits the real bottom topography quite well. Since the Stokes drift is the only nonlinear property we are interested in here, we do not need consider the effect of friction. Hence, the linear wave field follows from classic theories (Buchwald and Adams 1968; Gill and Schuman 1974; Gill 1982). The barotropic Rossby radius $a_{0}$ becomes $a_{0}=(g H)^{1 / 2} / f$. With $f=8.83 \times$ $10^{-5} \mathrm{~s}^{-1}$, we have for the Caspian shelf that $B^{2} / a_{0}^{2} \ll 1$. Accordingly, we can make the rigid lid approximation (Gill and Schuman 1974). Then the continuity equation allows us to introduce a streamfunction $\psi$, such that $u H=-\psi_{y}$ and $v H=\psi_{x}$. Introducing a traveling wave solution $\psi=H^{1 / 2} \phi(y) \exp [i(k x-\omega t)]$ (Gill 1982), where $k$ is the wavenumber and $\omega$ the frequency, the governing equation reduces to

$$
\phi_{y y}-l^{2} \phi=0,
$$

where $l^{2}=-\left[b^{2}+k^{2}-(2 b k f / \omega)\right]$. In our notation the subscript denotes partial derivation. Generally, the wavelength of CSWs reflects the horizontal scale of the wind field that generates them and is usually assumed to be much larger than the width of the shelf slope area. This assumption simplifies the analysis, and in particular the boundary condition at the outer edge of the shelf (Gill and Schuman 1974). This approximation will apply to the narrow shelf in the southern CS. Accordingly we take that $k^{2} \ll b^{2}$. In the shelf region (i.e., $y<B$ ), applying no cross-shelf flux boundary condition at the coast $(y=0)$, we find solution for (3) as

$$
\phi_{\text {in }}=A_{\text {in }} \sin l y,
$$

where $A_{\text {in }}$ is a constant and $l$ is the cross-shelf wavenumber. By inserting (4) into (3), we obtain the dispersion relation in this case:

$$
\omega=\frac{2 b f k}{b^{2}+l^{2}} .
$$

Furthermore, for a wave solution trapped against the shoreline, we require that

$$
\phi_{\text {out }} \rightarrow 0 \quad \text { as } \quad y \rightarrow \infty .
$$

Assuming $H_{\max }=$ const. for the outer shelf region $(y>B)$, the solutions of (3) become in the form of decreasing exponentials,

$$
\phi_{\text {out }}=A_{\text {out }} \exp (-k y),
$$

where $A_{\text {out }}$ is a constant. Utilizing continuity of fluxes $\left(\psi_{\text {in }}=\psi_{\text {out }}\right)$ and continuity of pressure $\left(\eta_{\text {in }}=\eta_{\text {out }}\right)$ at $y=$ $B$, which implies that (4) and (7) and their derivatives must be equal, we obtain

$$
\begin{aligned}
\psi_{\text {in }}=A e^{b(y-B)} \sin l y \exp [i(k x-\omega t)], & 0 \leq y \leq B, \\
\psi_{\text {out }}=A e^{k(B-y)} \sin l B \exp [i(k x-\omega t)], & y>B,
\end{aligned}
$$

where we have defined $A=A_{\text {in }} H_{0}^{1 / 2} e^{b B}$. Accordingly, from the boundary condition at $y=B$ that is, $\phi_{y}+b \phi=$ 0 , we obtain the equation for the transverse eigenmodes (e.g., Buchwald and Adams 1968):

$$
\tan l B=-\frac{l}{b}
$$




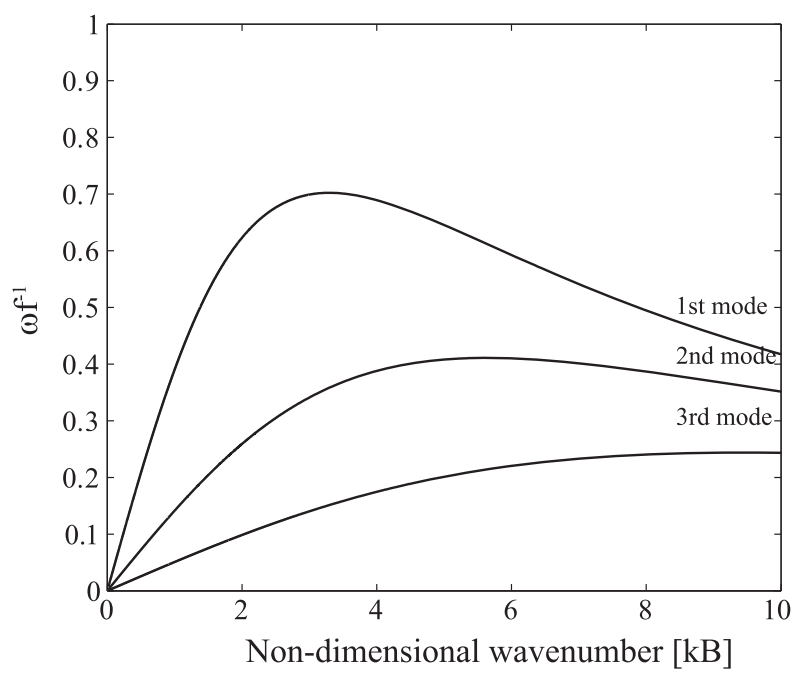

FIG. 8. Dispersion curves for the first three CSW modes over the southern shelf of the CS. The wavenumber is nondimensionalized by the shelf width $B$.

\section{Evidence of CSW}

For the Caspian shelf, with $B=26.6 \times 10^{3} \mathrm{~m}$ and $b=$ $0.87 \times 10^{-4} \mathrm{~m}^{-1}$, the lowest three modes become $l_{1}=$ $8.82 \times 10^{-5} \mathrm{~m}^{-1}, l_{2}=1.93 \times 10^{-4} \mathrm{~m}^{-1}$, and $l_{3}=3.45 \times$ $10^{-4} \mathrm{~m}^{-1}$, respectively. Figure 8 shows the continental shelf wave dispersion curves computed for the typical depth profile of the southern CS for the first three modes. Straight lines drawn between the origin and any point $k, \omega$ on the curves yield $\omega / k=2 f b /\left(b^{2}+l^{2}\right)$ from (5), which is the phase speed of the wave. The slope of the dispersion curve at any point $k, \omega$ is proportional to $d \omega / d k$, the group velocity or energy transport velocity of the wave. As noted by Buchwald and Adams (1968), the direction of energy transmission for shelf waves reverses at the maximum frequency for each mode. The direction of the phase velocity, however, remains the same (anticlockwise along the coast). For nondispersive long CSWs we note that the maximum frequency, that is, $\omega_{\max }=b f\left(b^{2}+l^{2}\right)^{-1 / 2}$, is always less than the inertial frequency. Furthermore, the maximum wavenumber is then given by $k_{\max }=\left(b^{2}+l^{2}\right)^{1 / 2}$ (Buchwald and Adams 1968), which for the Caspian shelf corresponds to wavelengths of approximately 51 , 31 , and $18 \mathrm{~km}$ for modes $1-3$, respectively. For wavelengths longer than this the group velocity, and hence the energy transport, will be in the same direction as the phase speed. As discussed in the previous section, we expect the most likely generation mechanism in the CS to we the wind field, and hence consider wavelengths shorter than those corresponding to the maximum frequency unlikely. Letting the real part of

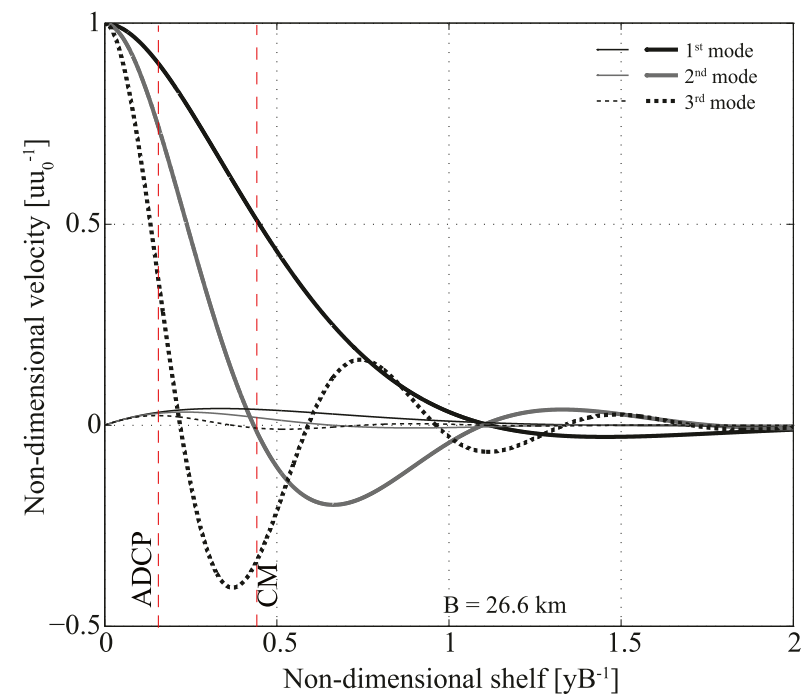

FIG. 9. Variation over the Caspian shelf for the nondimensional velocity of the first, second, and third CSW modes $\left(l_{1}=8.82 \times\right.$ $10^{-5} \mathrm{~m}^{-1}, l_{2}=1.93 \times 10^{-4} \mathrm{~m}^{-1}$, and $l_{3}=3.45 \times 10^{-4} \mathrm{~m}^{-1}$ ) from (10). Thick and thin lines represent nondimensional velocity components, i.e., $u(y) / u_{0}$ and $v(y) / u_{0}$, for the first three modes, respectively. Here, we present the first mode in black, second mode in dark gray, and third mode with a dashed line. The red dashed lines indicate the locations of current measurements.

$\psi_{\text {in }}$ represent the physical solution, we find for the linear part of the barotropic wave field:

$$
\begin{aligned}
& u=u_{0}\left(\frac{H_{0}}{H}\right)^{1 / 2}\left(\frac{b}{l} \sin l y+\cos l y\right) \cos (k x-\omega t), \\
& v=u_{0} \frac{k}{l}\left(\frac{H_{0}}{H}\right)^{1 / 2} \sin l y \sin (k x-\omega t), \\
& \eta=u_{0} \frac{c}{g}\left(\frac{H_{0}}{H}\right)^{1 / 2}\left[\left(\frac{b}{l}-\frac{f}{c l}\right) \sin l y+\cos l y\right] \cos (k x-\omega t),
\end{aligned}
$$

where $c=\omega / k$ is the phase speed of the wave. In (10) $u_{0}$ is the dimensional alongshore velocity at the coast. The vertical velocity follows straight away by integrating the continuity equation $w_{z}=-u_{x}-v_{y}$.

To visualize the modal structure, we define $u=$ $u(y) \cos (k x-\omega t)$ and $v=v(y) \sin (k x-\omega t)$ in (10). In Fig. 9 we have plotted the nondimensional variation and over the shelf for the three lowest modes. Note that for all modes the onshore flow is very small in comparison to the long-shore flow, and the wave motions are very weak beyond the foot of the continental margin.

Along the Caspian shelf, where CSWs travel from west to east, the observed $u$ should lead $v$, the onshore component, by $90^{\circ}$. Also for the deepest current meter, which is located well away from the surface and bottom 
frictional layers, we should see nearly elliptical clockwise motion (see Fig. 6). Equation (10) indicates that for CSWs the orthogonal components of flow $(u, v)$ should be in quadrature, that is, out of phase by $90^{\circ}$. We also note from (10) that both first and second mode have a velocity vector that rotates clockwise in time at the measurement sites, which is consistent with the measurements.

The solution (10) represents free waves. To quantify the nonlinear Stokes drift velocity, $u_{0}$ must be determined theoretically from the forcing field (the wind stress), for example, Gill and Schuman (1974), or be assessed from field observations, as we shall do here. However, it is useful to apply the analysis by Gill and Schuman to quantify the magnitude of the ratio between the second and first CSW modes generated by a periodic wind stress. Here, we consider the first two modes for further calculation. There is probably no need for considering higher CSW modes since very often the main part of the energy resides in these modes. In our notation, we find from Eq. (6.5) in Gill and Schuman (1974):

$$
r=\left|\frac{u_{02}}{u_{01}}\right| \sim \frac{k_{1} l_{2}^{2}\left[B\left(b^{2}-l_{1}^{2}\right)+b\right]}{k_{2} l_{1}^{2}\left[B\left(b^{2}+l_{2}^{2}\right)+b\right]} \sim 0.6 .
$$

We must stress that (10) are solutions of the linearized equations of motion. Accordingly, we must assume for the dominant nonlinear term that

$$
\frac{\left|u u_{x}\right|_{\max }}{\left|u_{t}\right|_{\max }}=\frac{|u(y)|}{2 c} \ll 1 .
$$

where $u(y)=u_{0}\left(H_{0}^{1 / 2} / H^{1 / 2}\right)[(b / l) \sin l y+\cos l y]$.

Observations from the southern CS shelf show wavelike behavior of the flow field. Ghaffari and Chegini (2010) showed that the autospectra of the wind and current fluctuations has high mutual coherence at about 6 days. Huyer et al. (1975) examined the correlation of the current, wind and the sea level fluctuations off the coasts of Oregon and Washington during the upwelling season. They noted that the signal at 6 days interval, showing high coherence between wind, current, and sea level fluctuations, may be due to forced shelf waves driven by the wind. In the same way, the current fluctuations obtained from observations off the southern coast of the CS might be due to remote winds forced CSWs. A very conservative estimate for the amplitude of the cross-shore velocity in Fig. 6 , is $u(y)=0.02 \mathrm{~m} \mathrm{~s}^{-1}$. Inserting this value at the offshore position $y=12.4 \mathrm{~km}$ in $u_{0}=u(y) l e^{b y}(b \sin l y+l \cos l y)^{-1}$, we obtain that $u_{01}=$ $0.3 \mathrm{~m} \mathrm{~s}^{-1}$ at the coast. Furthermore, the amplitude of the extreme event 6-16 September (see Fig. 3) is approximately $u_{\mathrm{amp}}=0.25 \mathrm{~m} \mathrm{~s}^{-1}$ above the mean value, and the period is nearly 6 days. The amplitude is measured $4 \mathrm{~km}$ off the coast. This fits well with earlier observations, for example, Bondarenko (2001) who reports currents with similar periods, and with amplitudes of order $0.2 \mathrm{~m} \mathrm{~s}^{-1}$ in the north and middle part of the CS shelf. Therefore, a realistic value for the first mode at the coast should be $u_{\mathrm{amp}}=0.3 \mathrm{~m} \mathrm{~s}^{-1}$.

We notice from Fig. 9 that the magnitude of $u(y)$ decays fairly quickly away from the coast. This indicates that if (12) is satisfied at the coast, where it reduces to $u_{0} /(2 c) \ll 1$, this condition will pose no problem over the central part of the shelf. Utilizing that $c_{1}=0.91 \mathrm{~m} \mathrm{~s}^{-1}$, for the first mode we find in the gravest case (at the coast) that $u_{01} /\left(2 c_{1}\right)=0.16$. For the second mode $c_{2}=0.32 \mathrm{~m} \mathrm{~s}^{-1}$, and with $u_{02}=0.6 u_{01}$, we find that $u_{02} /\left(2 c_{2}\right)=0.28$. This is at best a marginally acceptable value. However, as mentioned before, the ratio $\left|u_{2}(y)\right| /\left(2 c_{2}\right)$ attains much more acceptable values over the central part of the shelf. It therefore appears acceptable to use linearized theory to obtain the two first CSW modes over the Caspian shelf.

\section{Numerical experiment}

\section{a. Model setup}

To investigate the propagation of CSWs over the southern shelf of the CS, we have applied a two-dimensional depth-averaged version of the Finite-Volume Community Ocean Model (FVCOM; see Chen et al. 2003, 2007). FVCOM is an advanced coastal circulation model widely utilized for its ability to simulate spatially and temporally evolving geophysical conditions of complex and dynamic coastal regions. Model skill has been evaluated comparing with analytical or semianalytical solutions as well as with in situ data over large spatial and temporal scales (see, e.g., Chen et al. 2003, 2007; Cowles 2008; Isobe and Beardsley 2006; Weisberg and Zheng 2006; Frick et al. 2007; Cowles 2008).

In the absence of tides and open boundaries, atmospheric forcing is the main and primary mechanism for developing flow field over the Caspian shelf. Furthermore, due to the strongly variable topography, resulting flows are often spatially and temporally variable (Ghaffari et al. 2013). Hence, accurate simulation depends to a great extent upon the topography and wind data resolution. The present setup of FVCOM covers the entire CS basin including the shallow northern extension, uses a synthetic bathymetric field obtained and improved from diverse sources, for example, the General Bathymetric Chart of the Oceans (GEBCO), digitized bathymetry datasets of Iranian National Institute for Oceanography based on the 
Iranian National Cartographic Center maps (scale 1:25000), and the Caspian Environmental Program (CEP) datasets. One of the main advantages of the unstructured grid is the permitting of multiscale meshing in one model domain. Since the main focus in the present study is flow field variation associated with CSWs, we set highresolution mesh $\left(\sim 0.01^{\circ}\right)$ over the shelf in the southern and central basins and coarser resolution $\left(\sim 0.10^{\circ}\right)$ over the rest of the sea. The model simulates the barotropic mode, using a constant reference density. Bottom stress is based on a quadratic law, that is, $\tau_{b}=C_{d}\left|\mathbf{u}_{a}^{2}\right|^{1 / 2}\left(\mathbf{u}_{a}\right)$, with respect to depth-averaged currents $\mathbf{u}_{a}$. The drag coefficient $C_{d}$ is determined by matching a logarithmic bottom layer to the model at a height $z_{\mathrm{ab}}$ above the bottom, that is, $C_{d}=\max \left[k^{2} / \ln \left(z_{\mathrm{ab}} z_{o}^{-1}\right)^{2}, 0.0025\right]$, where $k=0.4$ is the von Kármán constant and $z_{o}$ is the bottom roughness parameter. External forcings is surface stress, which is extracted from ERA5 reanalysis (C3S 2017). Comparing to its predecessor ERA-Interim (Dee et al. 2011), ERA5 reanalysis is majorly improved in both temporal and spatial resolution senses enabling it directly to produce reasonable near-surface trends and variability. ERA5 (high resolution) data have a native spatial resolution of $0.28125^{\circ}$ and hourly wind parameters. A higher spatial resolution is technically possible, but this only oversamples the data and does not improve the accuracy of the data. Additionally, a higher spatial resolution does not necessarily imply better results in terms of, for example, correlations with measurements (Henson et al. 2012).

\section{b. Experiments}

For this study, first, we run the model with the atmospheric forcing from January 2003 to December 2005. Here 2D model captures most of the flow field variation, particularly, those extreme current events on 11-17 August 2003 and 6-18 September 2003 are well presented in the model (Fig. 3). Comparing with observations, the present setup gives reasonable results for the barotropic flow field along the Caspian coast, but it is very dependent on the quality of the atmospheric forcing. The CS currents are mainly wind induced, hence understanding the general wind pattern over the CS is essential. The current field is directly affected by these complexities in the wind field. Moreover, in the coastal regions, considering local wind effect is of importance for accurately simulating wind-driven currents, particularly, in storm conditions.

The development of the resulting velocity field, excluding the mean current, for eight points along the southern coast is shown as a Hovmöller plot in Fig. 10. Propagating CSW signals associated with those extreme events, which are not in line with local forcing, are readily evident. We note that contours slope from left to right, indicating low-frequency variability in the velocity field moving along the coast ( $x$ axis) with time ( $y$ axis) in a counterclockwise direction around the southern coast, where the signals are stronger at the central part. This shows that CSW energy was entering the southern shelf from the west, whereas the CSW itself could be generated by various mechanisms, for example, wind action (Adams and Buchwald 1969; Gill and Schuman 1974). In the absence of any strong local forcing, remotely triggered CSWs due to passing mesoscale atmospheric features is the most probable mechanism for explaining rather frequent CSW signals propagating along the southern shelf.

CSW phase speeds are estimated from the Hovmöller plot for the two wind stress events on 11-17 August 2003 and 6-18 September 2003. These events are chosen due to the sharp impulsive and isolated form of the local wind stress and the wave-like response of the flow field. The occurrence of current pulses on 6-18 September 2003 are two consecutive events for which we have rather good evidence of wave passage, based on the measurements. Current data showed passing waves with approximately 6-day periods, which were adjusted by local wind events (see Ghaffari and Chegini 2010). The Hovmöller plot reveals that phase speed is high between points 1 and 3, approximately $1.0 \mathrm{~m} \mathrm{~s}^{-1}$, then between points 3 and 7 is low at around $0.32-0.42 \mathrm{~m} \mathrm{~s}^{-1}$. Again the phase speed retains a higher value $\left(\approx 0.9 \mathrm{~m} \mathrm{~s}^{-1}\right)$ between points 7 and 8 .

On both ends of the selected shelf region, that is, points $1-3$ and $7-8$, where the inner shelf is wide, the estimates are in a good agreement with the phase speed that we found for the first mode in the gravest case. Over the central part of the shelf, however, the Hovmöller plot indicates a lower phase speed, which is consistent with the second mode. The frequencywavenumber pairs corresponding to a period of 6 days and the phase velocities found from the Hovmöller plot are shown together with the theoretically derived dispersion curves in Fig. 11. As can be seen, the wave features in the model correspond to a mode $1 \mathrm{CSW}$ between points $1-3$ and $7-8$, while the model wave response closely resembles a mode $2 \mathrm{CSW}$ along points 3-7. Note that $\left|u_{2}(y) /\left(2 c_{2}\right)\right|$ attains much more acceptable values over the central part of the shelf. At point 3 , the shelf varies from a relatively wide inner shelf to an almost no inner shelf. The latter one was first treated by Buchwald and Adams (1968), and we considered it as a typical shelf model for the southern CS. Here, the shelf itself possesses the smallest width that permits much shorter waves. Therefore, all firstmode CSWs can reach this point, but onward this 

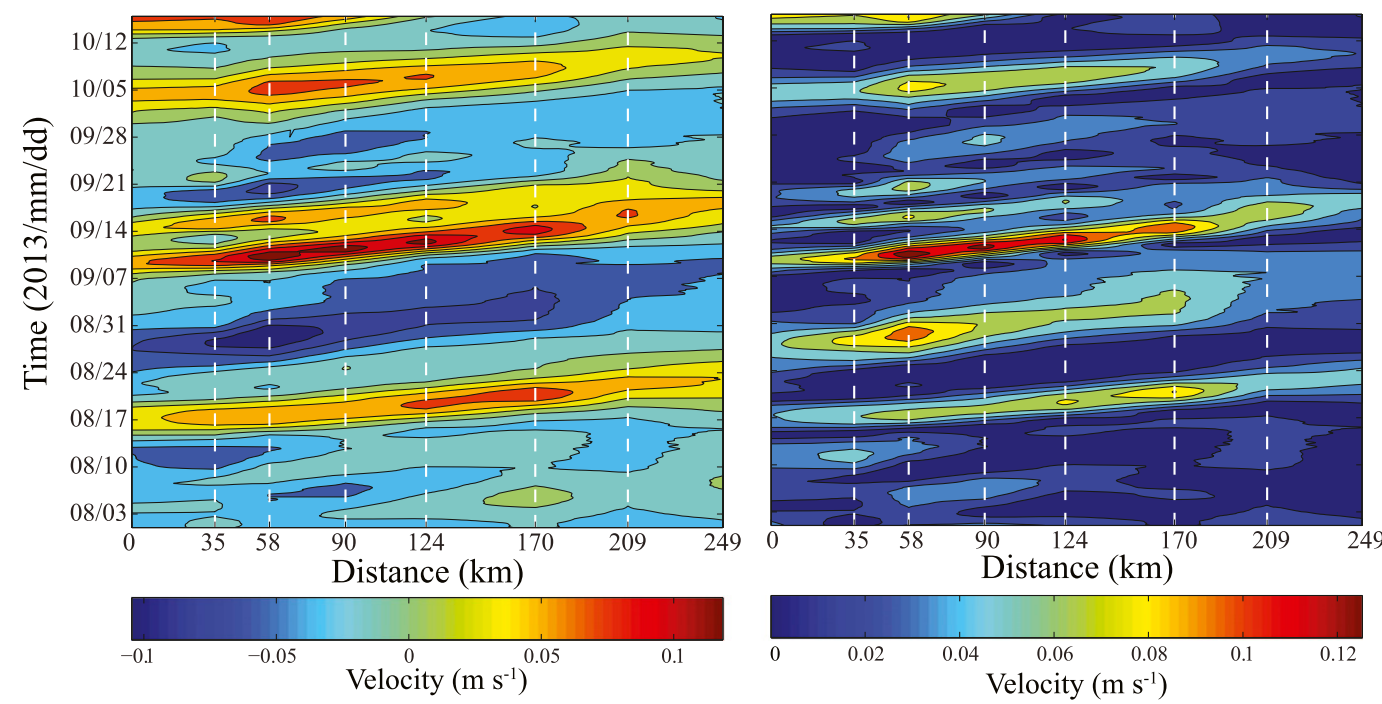

FIG. 10. Hovmöller plots of the (left) alongshore velocity and (right) flow field speed, for the eight points shown in Fig. 1, representing the isolated storm events showed in Fig. 3. The vertical white lines correspond to the points shown in Fig. 1, starting with the westernmost point (at left) going eastward (to the right).

point, the wave energy may travel as second-mode CSWs. This may also lead to CSW breaking in this region (Drivdal et al. 2016), which in turn may contribute to the strong currents observed here.

To investigate the flow field response to the atmospheric forces and study possible propagation of pure remotely generated CSW along the southern coast of the CS, we configure semi-idealized experiments based on wind stress event on 11-17 August 2003. In this experiment, in order to study free waves response without atmospheric interference, we exposed the central basin to an idealized impulsive wind stress similar to what we see in Fig. 3. The model is ramped up to the pick impulse stress field over 10 days, followed by an abrupt termination. This permits the flow field to respond to the impulsive force and oscillate without external forcing interference (except frictional damping). The corresponding flow field development for eight points along the southern coast is shown as a Hovmöller plot in Fig. 12, where the entering of the CSW energy to the southern shelf from the west is evident. Furthermore, the frequency-wavenumber pairs corresponding to a period of 6 days and the phase velocities extracted from the semi-idealized Hovmöller diagram fit nicely with the theoretically derived dispersion curves. Here also the idealized model response mainly on first mode CSW for the western and eastern sides of the shelf and falls into the second mode for points 3-7. The resulted features strengthen the hypothesis that the central basin of the CS is the main candidate region for the generation of these propagating signals.
This region is often subject to mesoscale weather systems that range from small local front systems to synoptic scales. Those features are associated with both weak and intense cold-cored systems from the Siberian high to warm-cored midlatitude westerly systems. Furthermore, mechanically induced circulation caused by flow across the high Caucasus Mountains to the west and thermally induced

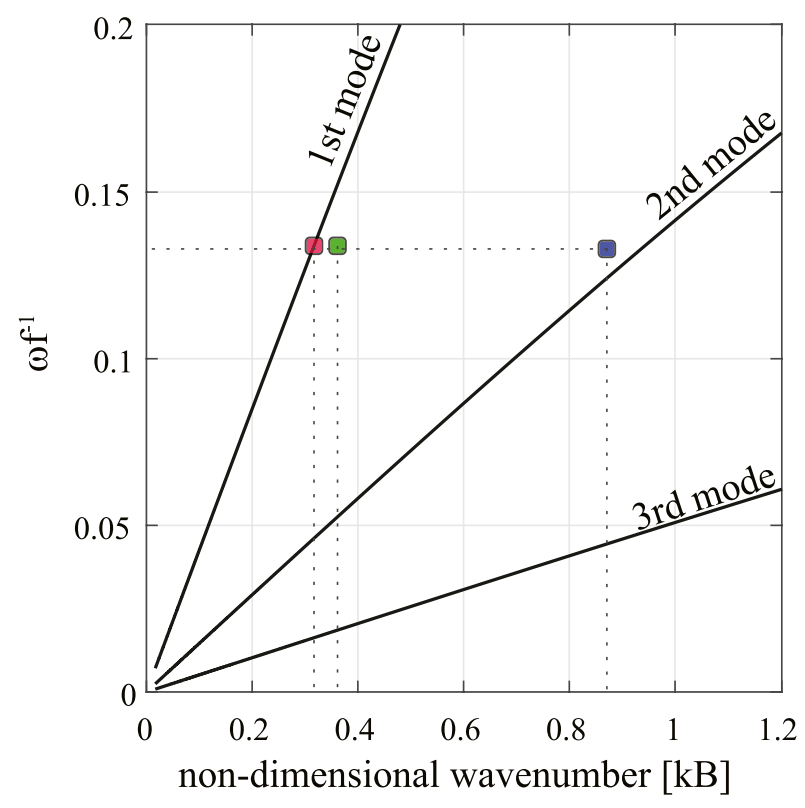

FIG. 11. Zoomed version of Fig. 8 including the model frequencywavenumber pairs for phase velocities of $c=1.0 \mathrm{~m} \mathrm{~s}^{-1}$ (red), $c=$ $0.37 \mathrm{~m} \mathrm{~s}^{-1}$ (blue), and $c=0.9 \mathrm{~m} \mathrm{~s}^{-1}$ (green). The phase velocities correspond to the velocities found from Fig. 12 for points 1-3, 3-7, and $7-8$, respectively. 

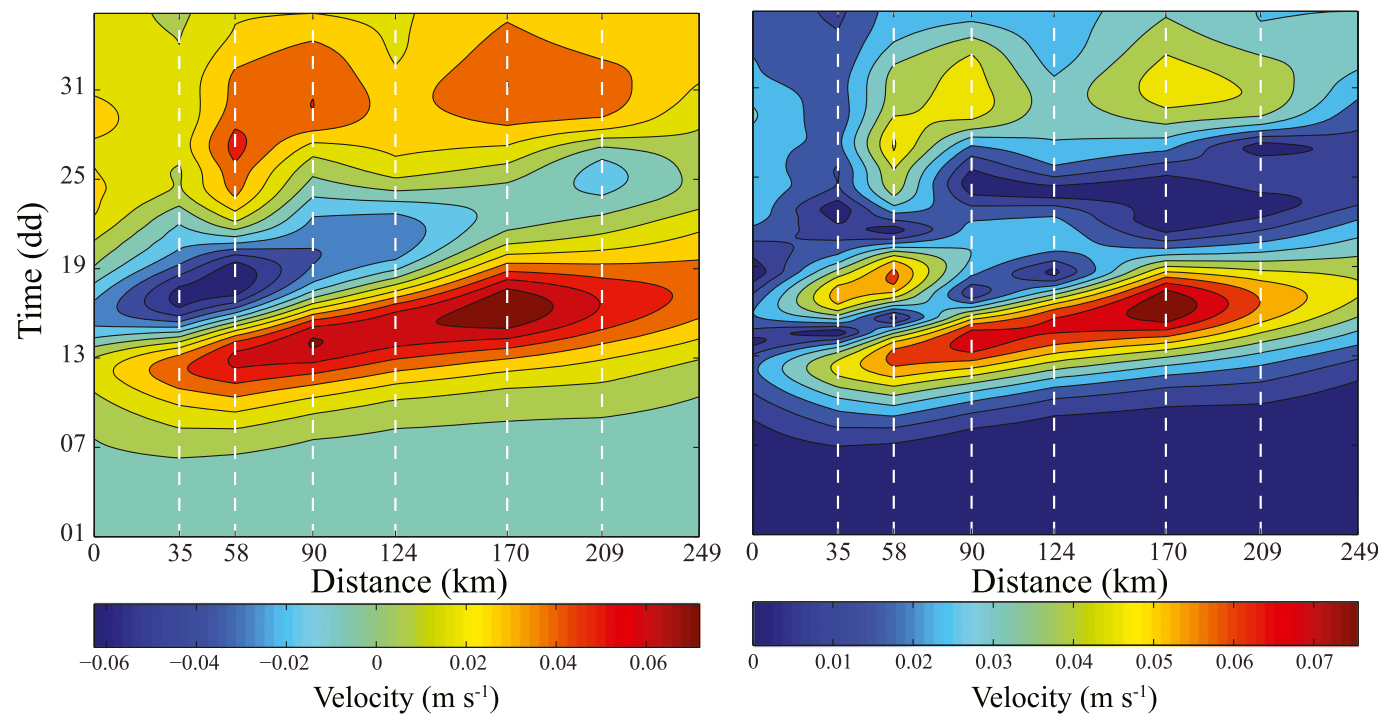

FIG. 12. Hovmöller plots of the flow field velocity similar to Fig. 10, but for an idealized isolated storm event over the central CS basin.

wind caused by the surface heating from the relatively warm sea, make this region a favorable location for quasi-stationary cyclonic features (Shenk 1965).

\section{The Stokes drift velocity}

The Stokes velocity $\mathbf{v}_{S}$ to second order in wave amplitude can be written (Longuet-Higgins 1953)

$$
\mathbf{v}_{S}=\int(\mathbf{v} d t) \cdot \nabla \mathbf{v},
$$

where $\mathbf{v}$ is the linear Eulerian wave velocity. To obtain the mean value, we must average over the wave cycle. For one single progressive wave component this can be done by averaging over one wave period, or over one wavelength. For a superposition of waves, we must average in time and space. In the present problem we assume that the relevant linear CSW field is composed of the first and second shelf mode $\left(u=u_{1}+u_{2}, v=v_{1}+\right.$ $v_{2}$ ). Hence from (10),

$$
\begin{aligned}
u= & \frac{H_{0}^{1 / 2}}{H^{1 / 2}}\left\{u_{01}\left(\frac{b}{l_{1}} \sin l_{1} y+\cos l_{1} y\right) \cos \left(k_{1} x-\omega t\right)\right. \\
& \left.+u_{02}\left(\frac{b}{l_{2}} \sin l_{2} y+\cos l_{2} y\right)\left[\cos \left(k_{2} x-\omega t\right)\right]\right\}, \\
v= & \frac{H_{0}^{1 / 2}}{H^{1 / 2}}\left[u_{01} \frac{k_{1}}{l_{1}} \sin l_{1} y \sin \left(k_{1} x-\omega t\right)\right. \\
& \left.+u_{02} \frac{k_{2}}{l_{2}} \sin l_{2} y \sin \left(k_{2} x-\omega t\right)\right] .
\end{aligned}
$$

The Stokes velocity is obtained by introducing (14) and (15) into (13). We define Stokes drift by averaging (13) over the wave period $T=2 \pi / \omega$ and the length scale $L=2 \pi /\left(k_{2}-k_{1}\right)$. This process is denoted by an overbar. The cross-shore Stokes drift here is zero, and the alongshore Stokes drift becomes

$$
\begin{aligned}
\bar{u}_{S}= & \overline{\left(\int \mathbf{v} d t\right) \cdot \nabla u}=\frac{u_{01}^{2} H_{0}}{2 H c_{1}}\left(\frac{b}{l_{1}} \sin 2 l_{1} y+\cos 2 l_{1} y\right) \\
& +\frac{u_{02}^{2} H_{0}}{2 H c_{2}}\left(\frac{b}{l_{2}} \sin 2 l_{2} y+\cos 2 l_{2} y\right) .
\end{aligned}
$$

For the relative importance of the contributions to the Stokes drift from the first and second mode, we assume from Gill and Schuman (1974), for example, (10), that $u_{02}^{2} / u_{01}^{2}=r^{2}=0.36$. For the Stokes drift we must require that

$$
\left|\bar{u}_{S}\right| / c_{1,2} \sim u_{01,2}^{2} /\left(2 c_{1,2}^{2}\right) \ll 1,
$$

which is potentially much easier to fulfill than (12) due to the square of the small perturbations.

Since long CSWs are nondispersive, that is, $c=$ $\omega / k=2 b f /\left(b^{2}+l^{2}\right)$, where $l$ is given by (9), we note from (16) that the Stokes drift is completely determined by the shelf geometry and the linear velocity amplitudes $u_{01}, u_{02}$ at the coast. We can now make quantitative estimates of the Stokes drift from (16). In Fig. 13 we have displayed the variation of the Stokes drift over the shelf when $u_{01}=0.3 \mathrm{~m} \mathrm{~s}^{-1}$ and the period is 6 days. The influence of the second mode is assessed from (11). 


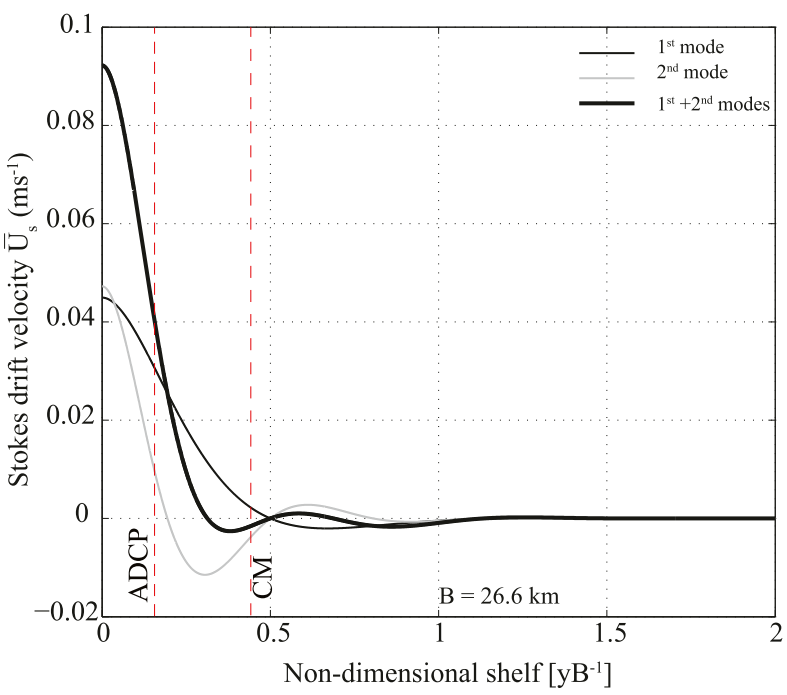

FIG. 13. Variation of the Stokes drift $\bar{u}_{S}$ across the southern CS shelf.

We note that the Stokes drift has its maximum at the coast and varies essentially over the inner $1 / 3$ part of the shelf. Again, with $c_{1}=0.91 \mathrm{~m} \mathrm{~s}^{-1}$ and $c_{2}=0.32 \mathrm{~m} \mathrm{~s}^{-1}$ for the two first modes, we infer from the values in Fig. 13 that the condition (17) is well fulfilled.

The Stokes drift is inherent in progressive waves. We have here calculated it for CSWs to second order in wave amplitude. A more comprehensive study of the wave-induced drift can be found in Flierl (1981), where higher-order approximations are discussed. In cases where the linearization assumption is marginally justifiable, as for our second mode, a full analysis including the nonlinear advection terms would not yield wave components that significantly altered the order of magnitude of the Stokes drift calculated here. Realizing that mean wave-drift currents of order $0.1 \mathrm{~m} \mathrm{~s}^{-1}$ are comparable with currents induced by moderate winds, the present analysis clearly demonstrates that the nonlinear Stokes drift current cannot be neglected over the shallow part of the shelf in the southern CS.

\section{Discussion and conclusions}

Traditionally, tides, winds, and density differences are considered as the main influential mechanisms contributing to transport at the ocean margin (Huthnance 1995). However, it is well known that periodic shelf wave motion can create strong currents; see, for example, the model results of Martinsen et al. (1979). Although strong longperiodic currents may cause movement of bottom sediments and inflict damage to the foundations of subsea constructions, it is the mean flow, obtained by averaging over the wave cycle, which yields a net transport of matter along the shelf. Röhrs et al. (2014) showed that the wave-induced drift (i.e., Stokes drift) is relevant for the transport of Northeast Arctic cod eggs and larvae, where the wave effects yield significant changes in the transport and provide more realistic distribution profiles. Delpey et al. (2014) showed that wave-induced circulation in a small estuarine bay is larger than that due to the wind. Furthermore, Inall et al. (2015) and Fraser and Inall (2018) showed the significance of Stokes drift in semienclosed fjord. However, wave-driven significance in the marginal seas and enclosed/semienclosed basins has not yet been fully investigated. This is particularly important for the drift of pollutants and neutral tracers. The present study demonstrates that the Stokes drift associated with CSWs can have a significant influence on such transports along the shelf of the southern CS.

It should be emphasized what are the limitations of our study. In the theoretical consideration of CSWs we have used a typified/idealized shelf profile assuming a straight coast of the uniform cross section for the southern shelf of the CS. However, real continental shelves are anything but straight and uniform. Here, essentially, we have focused on the central part of the southern shelf, and in that sense, the results must be viewed in a qualitative way.

Since barotropic CSW theory has been successful in describing observed low-frequency signals at several locations (Drivdal et al. 2016; Inall et al. 2015), we have here considered CSWs in a purely barotropic ocean. Of course, stratification can cause current fluctuations, and its presence is expected to shift the waves toward higher frequency (Huthnance 1978; Brink 2006; Sansón 2012). In fact, the CS has low salinity and the density stratification mimics the temperature structure. Typical seasonal thermocline locates at $30-\mathrm{m}$ depth in summer for almost whole basin. The stratification is weaker but does not vanish in winter. For example, in winter 2008 the seasonal thermocline reached almost $100 \mathrm{~m}$ (Ghaffari et al. 2010), where the water mass was still weakly stratified. We have estimated the Burger number (see, e.g., Huthnance 1975); $\mathrm{Bu}=[N H /(f L)]^{2}$. Using typical values for the Caspian shelf $(L=30 \mathrm{~km}, f=8.8 \times$ $\left.10^{-5} \mathrm{~s}^{-1}, H=800 \mathrm{~m}\right)$, and typical stratification beneath the shallow thermocline at $60 \mathrm{~m}\left(N=10^{-3} \mathrm{~s}^{-1}\right.$; see Weber and Ghaffari 2014), we obtain $\mathrm{Bu} \sim 0.1$, which indicates that the effect of stratification on CSWs in the southern CS is small. Ghaffari et al. (2013) showed that while in the central basin the barotropic model results show a high correlation with observations, in the southern basin the equivalent barotropic model is successful in describing the flow field. They also argued that the vertical stratification might be important in the southern basin. The implication to our problem is that in 
the transition from the central to southern basin the waves may shift toward shorter wavelengths due to the somewhat stronger stratification.

Acknowledgments. This work was supported under the FAABulous project Grant 243702 funded by The Research Council of Norway and by the Glider project financed by The Research Council of Norway Demo2000 and ConocoPhillips Norge (Grant 269188). Jan Erik H. Weber gratefully acknowledges financial support from The Research Council of Norway through Grant 280625 (Dynamics of floating ice).

\section{REFERENCES}

Adams, J. K., and V. T. Buchwald, 1969: The generation of continental shelf waves. J. Fluid Mech., 35, 815-826, https://doi.org/ 10.1017/S0022112069001455.

Baidin, S. S., and A. N. Kosarev, 1986: The Caspian Sea: Hydrology and Hydrochemistry. Nauka, $261 \mathrm{pp}$.

Bohluly, A., F. S. Esfahani, M. Montazeri Namin, and F. Chegini, 2018: Evaluation of wind induced currents modeling along the Southern Caspian Sea. Cont. Shelf Res., 153, 50-63, https:// doi.org/10.1016/j.csr.2017.12.008.

Bondarenko, A. L., 2001: Wind-induced currents in seas. Water Resour., 28, 105-107, https://doi.org/10.1023/A:1018893116810.

Brink, K. H., 1991: Coastal-trapped waves and wind-driven currents over the continental shelf. Annu. Rev. Fluid. Mech., 23, 389-412, https://doi.org/10.1146/annurev.fl.23.010191.002133.

, 2006: Coastal-trapped waves with finite bottom friction. Dyn. Atmos. Oceans, 41, 172-190, https://doi.org/10.1016/ j.dynatmoce.2006.05.001.

Buchwald, V. T., and J. K. Adams, 1968: The propagation of continental shelf waves. Proc. Roy. Soc. London, A305, 235-250, https://doi.org/10.1098/rspa.1968.0115.

C3S, 2017: ERA5: Fifth generation of ECMWF atmospheric reanalyses of the global climate.Copernicus Climate Change Service (C3S) Data Store, accessed 1 June 2018, https:// cds.climate.copernicus.eu/cdsapp\#!/dataset/reanalysis-era5single-levels-monthly-means? $\mathrm{tab}=$ overview.

Chen, C., H. Liu, and R. C. Beardsley, 2003: An unstructured grid, finite-volume, three-dimensional, primitive equations ocean model: Application to coastal ocean and estuaries. J. Atmos. Oceanic Technol., 20, 159-186, https://doi.org/10.1175/15200426(2003)020<0159:AUGFVT>2.0.CO;2.

- H. Huang, R. C. Beardsley, H. Liu, Q. Xu, and G. Cowles, 2007: A finite volume numerical approach for coastal ocean circulation studies: Comparisons with finite difference models. J. Geophys. Res., 112, C03018, https://doi.org/10.1029/2006JC003485.

Cowles, G. W., 2008: Parallelization of the Fvcom coastal ocean model. Int. J. High Perform. Comput. Appl., 22, 177-193, https://doi.org/10.1177/1094342007083804.

Cutchin, D. L., and R. L. Smith, 1973: Continental shelf waves: Low-frequency variations in sea level and currents over the Oregon continental shelf. J. Phys. Oceanogr., 3, 73-82, https:// doi.org/10.1175/1520-0485(1973)003<0073:CSWLFV>2.0.CO;2.

Dee, D. P., and Coauthors, 2011: The ERA-Interim reanalysis: Configuration and performance of the data assimilation system. Quart. J. Roy. Meteor. Soc., 137, 553-597, https://doi.org/ 10.1002/qj.828.
Delpey, M. T., F. Ardhuin, P. Otheguy, and A. Jouon, 2014: Effects of waves on coastal water dispersion in a small estuarine bay. J. Geophys. Res. Oceans, 119, 70-86, https://doi.org/10.1002/ 2013JC009466.

Drivdal, M., J. E. H. Weber, and J. B. Debernard, 2016: Dispersion relation for continental shelf waves when the shallow shelf part has an arbitrary width: Application to the shelf west of Norway. J. Phys. Oceanogr., 46, 537-549, https://doi.org/ 10.1175/JPO-D-15-0023.1.

Flierl, G. R., 1981: Particle motions in large-amplitude wave fields. Geophys. Astrophys. Fluid Dyn., 18, 39-74, https://doi.org/ 10.1080/03091928108208773.

Fraser, N. J., and M. E. Inall, 2018: Influence of barrier wind forcing on heat delivery toward the Greenland ice sheet. J. Geophys. Res. Oceans, 123, 2513-2538, https://doi.org/ 10.1002/2017JC013464.

Frick, W. E., T. Khangaonkar, A. C. Sigleo, and Z. Yang, 2007: Estuarine-ocean exchange in a North Pacific estuary: Comparison of steady state and dynamic models. Estuarine Coastal Shelf Sci., 74, 1-11, https://doi.org/10.1016/J.ECSS.2007.02.019.

Ghaffari, P., and V. Chegini, 2010: Acoustic Doppler current profiler observations in the Southern Caspian Sea: Shelf currents and flow field off feridoonkenar bay, Iran. Ocean Sci., 6 , 737-748, https://doi.org/10.5194/os-6-737-2010.

_ _ and J. E. H. Weber, 2014: Mass transport in the Stokes edge wave for constant arbitrary bottom slope in a rotating ocean. J. Phys. Oceanogr., 44, 1161-1174, https://doi.org/10.1175/ JPO-D-13-0171.1.

— H. A. Lahijani, and J. Azizpour, 2010: Snapshot observation of the physical structure and stratification in deep-water of the South Caspian Sea (western part). Ocean Sci., 6, 877-885, https://doi.org/10.5194/os-6-877-2010.

_, P. E. Isachsen, and J. H. LaCasce, 2013: Topographic effects on current variability in the Caspian Sea. J. Geophys. Res. Oceans, 118, 7107-7116, https://doi.org/10.1002/2013JC009128.

Gill, A. E., 1982: Atmosphere-Ocean Dynamics. Academic Press, $662 \mathrm{pp}$.

, and E. H. Schumann, 1974: The generation of long shelf waves by the wind. J. Phys. Oceanogr., 4, 83-90, https://doi.org/ 10.1175/1520-0485(1974)004<0083:TGOLSW > 2.0.CO;2.

Henson, W. L. W., J. G. McGowan, and J. F. Manwell, 2012: Utilizing reanalysis and synthesis datasets in wind resource characterization for large-scale wind integration. Wind Eng., 36, 97-109, https://doi.org/10.1260/0309-524X.36.1.97.

Huthnance, J. M., 1975: On trapped waves over a continental shelf. J. Fluid Mech., 69, 689-704, https://doi.org/10.1017/ S0022112075001632.

_ 1978: On coastal trapped waves: Analysis and numerical calculation by inverse iteration. J. Phys. Oceanogr., 8, 74-92, https:// doi.org/10.1175/1520-0485(1978)008<0074:OCTWAA $>2.0$.CO;2. - 1995: Circulation, exchange and water masses at the ocean margin: The role of physical processes at the shelf edge. Prog. Oceanogr., 35, 353-431, https://doi.org/10.1016/0079-6611(95) 80003-C.

Huyer, A., B. M. Hickey, J. D. Smith, R. L. Smith, and R. D. Pillsbury, 1975: Alongshore coherence at low frequencies in currents observed over the continental shelf off Oregon and Washington. J. Geophys. Res., 80, 3495-3505, https://doi.org/ 10.1029/JC080i024p03495.

Inall, M. E., F. Nilsen, F. R. Cottier, and R. Daae, 2015: Shelf/Fjord exchange driven by coastal-trapped waves in the Arctic. J. Geophys. Res. Oceans, 120, 8283-8303, https://doi.org/ 10.1002/2015JC011277. 
Isobe, A., and R. C. Beardsley, 2006: An estimate of the crossfrontal transport at the shelf break of the East China sea with the finite volume coastal ocean model. J. Geophys. Res., 111, C03012, https://doi.org/10.1029/2005JC003290.

Kenyon, K. E., 1969: Note on Stokes' drift velocity for edge waves. J. Geophys. Res., 74, 5533-5535, https://doi.org/ 10.1029/JC074i023p05533.

LeBlond, P. H., and L. A. Mysak, 1978: Waves in the Ocean. Elsevier, 602 pp.

Longuet-Higgins, M. S., 1953: Mass transport in water waves. Philos. Trans. Roy. Soc. London, A245, 535-581, https:// doi.org/10.1098/rsta.1953.0006.

_ 1965: Some dynamical aspects of ocean currents. Quart. J. Roy. Meteor. Soc., 91, 425-451, https://doi.org/10.1002/qj.49709139005.

Martinsen, E. A., B. Gjevik, and L. P. Röd, 1979: A numerical model for long barotropic waves and storm surges along the western coast of Norway. J. Phys. Oceanogr., 9, 1126-1138, https://doi.org/ 10.1175/1520-0485(1979)009<1126:ANMFLB > 2.0.CO;2.

Mysak, L. A., 1984: Topographic waves in lakes. Hydrodynamics of Lakes, K. Hutter, Ed., Springer, 81-128.

Phillips, O. M., 1977: The Dynamics of the Upper Ocean. 2nd ed. Cambridge University Press, $336 \mathrm{pp}$.

Röhrs, J., K. H. Christensen, F. Vikeb $\varnothing$, S. Sundby, Ø. Saetra, and G. Broström, 2014: Wave-induced transport and vertical mixing of pelagic eggs and larvae. Limnol. Oceanogr., 59, 1213-1227, https://doi.org/10.4319/lo.2014.59.4.1213.
Sansón, L. Z., 2012: Simple models of coastal-trapped waves based on the shape of the bottom topography. J. Phys. Oceanogr., 42, 420-429, https://doi.org/10.1175/JPO-D11-053.1.

Shenk, W. E., 1965: Analysis of a caspian sea vortex. Mon. Wea. Rev., 93, 613-617, https://doi.org/10.1175/1520-0493(1965) 093<0613:AOACSV $>2.3$.CO;2.

Stokes, G. G., 1847: On the theory of oscillatory waves. Trans. Cambridge Philos. Soc., 8, 441-455.

Weber, J. E. H., and P. Ghaffari, 2009: Mass transport in the Stokes edge wave. J. Mar. Res., 67, 213-224, https://doi.org/10.1357/ 002224009789051182.

— continental shelf waves. Cont. Shelf Res., 35, 108-116, https:// doi.org/10.1016/j.csr.2012.01.001.

_ , and P. Ghaffari, 2014: Mass transport in internal coastal kelvin waves. Eur. J. Mech., 47B, 151-157, https://doi.org/ 10.1016/j.euromechflu.2014.02.006.

Weisberg, R. H., and L. Zheng, 2006: Circulation of tampa bay driven by buoyancy, tides, and winds, as simulated using a finite volume coastal ocean model. J. Geophys. Res., 111, C01005, https://doi.org/10.1029/2005JC003067.

Zaker, N. H., P. Ghaffari, S. Jamshidi, and M. Nouranian, 2011: Currents on the southern continental shelf of the Caspian Sea off Babolsar, Mazandaran, Iran. J. Coastal. Res., SI64, 19891997, https://www.jstor.org/stable/26482525. 